\title{
FACTIBILIDAD GOMERGIAL PARA ESTABLECER UNA MARCA EN PRODUCTOS TEXTILES CON INCLUSIÓN DEL TRABAJO DE ILUSTRAGIÓN DE DISEÑADORES GRÁFICOS DE GUENCA
}

\author{
María Elena Castro Rivera \& \\ Mateo Andrés Pacheco Vintimilla.
}

Resumen

El análisis de factibilidad comercial para establecer una marca textil que vincule trabajos de ilustración gráfica de diferentes diseñadores gráficos cuencanos para plasmarlos en prendas textiles, tiene como propósito conocer el interés y aceptación de los consumidores y diseñadores gráficos cuencanos. La investigación tiene etapas como el desarrollo de la industria textil nacional, la relación entre el diseño gráfico y la industria textil, conceptos de marca y posteriormente el estudio de mercado utilizando métodos cualitativo y cuantitativo. La parte cuantitativa se real izó mediante encuestas a consumidores y diseñadores gráficos. Como producto de la investigación se obtuvieron resultados positivos.

Palabras clave: Factibilidad comercial, investigación de mercados, marca textil, industria textil, diseño gráfico, ilustración gráfica, innovación.

Keywords: Commercial feasibility, market research, textile brand, textile industry, graphic design, graphic illustration, innovation. 


\section{Análisis de la industria textil local}

Haciendo un recuento del desarrollo de la industria textil en el Ecuador se ha determinado que el punto donde despega la misma se remonta a inicios de la década de los noventa. Los índices muestran un desarrollo claro, la Asociación de Industriales Textiles del Ecuador AlTE, (2014) da información actual y de períodos pasados, como que en el año 2000 la cantidad en dólares por la exportación de productos textiles fue de 67.802,088 de dólares y hasta el año 2010 subió a 157.285,982 de dólares, mostrando un mayor desarrollo en esta industria.

Según la AlTE (2014), la producción textil está más marcada en ciertas provincias del Ecuador como son Pichincha, Tungurahua, Imbabura, Azuay y Guayas. Éstas han mejorado su producción y usan mayor mano de obra, ya que esta industria se encuentra en segundo puesto en el sector manufacturero del país después de los alimentos, bebidas y tabacos. La tecnología es parte del aumento productivo de esta industria, que ha evolucionado con el paso de los años, donde muestra los beneficios para los productores y emprendedores en la elaboración y distribución de estos productos.

Dentro de la industria textil local existen preguntas ante problemas como el alto nivel de importaciones de productos textiles al país, el ingreso monetario por exportaciones es menor en comparación con el de los competidores de países vecinos. A pesar del desarrollo en la industria textil en el país, no se está explotando esta industria al máximo 0 aprovechando todo el potencial que podría brindar la misma. Un estudio realizado por el Instituto de Promoción de Exportaciones e Inversiones en el Ecuador, en su publicación Análisis sectorial de textiles y confecciones señala que:

Debido al reciente estancamiento por falta de innovación de diseños, marcas propias y tecnología, que ha permitido el ingreso de productos extranjeros, el sector textil ecuatoriano ha venido realizando esfuerzos con el objetivo principal de mejorar los índices de producción actuales, e innovar en la creación de nuevos productos que satisfagan la demanda internacional (2012).

Esto muestra un factor débil de la industria textil local que es el descuido en la innovación; lo que no permite llevar la producción y el diseño a la par con las tendencias y modas actuales del mercado global. Este es uno de los motivos por lo que en este medio se comercializa un alto número de productos textiles importados, dejando de lado al producto textil local.

Entre las soluciones al estancamiento de la industria textil local también se encuentran planes que el gobierno ha implementado para incentivar la producción local, como es el certificado de, ¡Mucho mejor! si es hecho en Ecuador y algunas políticas arancelarias aplicadas en el país para intentar parar la alta importación de productos textiles de otros países como China y los Estados Unidos. Uno de los tantos problemas 
que existen en la industria textil local es la falta de personal calificado para elaborar estos productos, los altos costos que tienen las materias primas importadas, lo que incide en los elevados precios de los productos terminados (Fuentes, 2013).

\section{La ilustración en el diseño gráfico local}

La ilustración son las imágenes que representan un mensaje; pueden ser los dibujos, pinturas, grabados que se plasman y comunican con o sin palabras, lo que el autor propone en su tema de obra.

Según la definición de la ilustración en el diseño gráfico, Almela señala:

La ilustración como síntoma y protagonista del dilema inmediato que marca la proximidad y las distancias presentes entre el producto del diseño y el producto de arte, todavía dentro del terreno de la creación individual y concreta de una imagen, donde muchas veces la única diferencia estriba en el enfoque funcional entre la ilustración y un cuadro: Un ilustrador entrega un original para su reproducción, mientras el artista entrega el original de la obra para ser comercializado por galería (2006).

La ilustración con el tiempo transcurrido se ha adaptado a las nuevas tecnologías, técnicas, sus aplicaciones, medios y propósitos, llegando a ser una disciplina de compleja especialización; sin embargo, el objetivo siempre será el mismo, comunicar. Aunque la ilustración ha sido denominada un arte menor por la reproducción de la obra que se realiza a pesar de la excelencia que tenga, ésta ha llevado su importancia por saber dirigir la información, su forma de comunicar, educar, documentar, expresar ideas, y desarrollarse dentro del comercio, de la industria gráfica estando su importancia económica en función de los usos 0 aplicaciones que se dé a este recurso (Almela, 2008).

Actualmente en la ciudad de Cuenca se han dado a conocer algunos ilustradores gráficos por sus buenas obras y sus aportes en ciertos medios, como revistas, publicidad empresarial, libros, periódicos, etc. Entre los ilustradores cuencanos se obtuvo una lista que da a conocer una parte de ilustradores gráficos publicados en la revista digital de Ochoa (2013), entre los que encontramos: Pedro Sevilla, Daniel Ojeda, Carmen Páez, Daniel Vicuña, Diana Vázquez, Cristopher Guamán, Gabriela Corral, Salomón Sarmiento, Milton Cárdenas, Fernando Méndez, Verónica Arce, Galo Mosquera, Rene Martínez, David Arévalo, Cristian Merchán, Juan Dávila, Juan Fernández, Mariela Barzallo, Santiago Calle, Rafael Carrasco, Darwin Parra, Diego Molina, Roberto Ortiz, Juan Asmal, Edison Zhinín, Jossue Cárdenas, Daniela Patiño, Paul Galán, Sebastián Pacheco, Andrés Olingi, Johnny Gavilanes, entre otros.

Estos son algunos de los ilustradores cuencanos cuyo trabajo sobresale local- 
mente, con la expectativa de expandir su arte fuera de la ciudad, de tal manera que sobrepasen fronteras y lleguen a más lugares incluyendo a nivel internacional.

Para conocer cómo se desarrolla la ilustración en el diseño gráfico en Cuenca, Sebastián Pacheco y Juan Dávila como diseñadores gráficos que forman parte del mundo de la ilustración y cuyas obras y trabajo han sido reconocidas nacional como internacionalmente; colaboraron con sus opiniones ante este tema.

El diseño gráfico y la aplicación de ilustración gráfica en la ciudad de Cuenca han tenido un crecimiento significativo a pesar de que muchas personas desconocen el trabajo profesional que poseen los trabajos de ilustración.

En la ciudad existen personas talentosas, que han logrado hacerse notar gracias a los diferentes medios de comunicación, como también el intercambio de conocimientos que son útiles para el artista al momento de crear, está en los diseñadores gráficos e ilustradores continuar con este proceso de crecimiento artístico fomentando y apoyando a los nuevos talentos.

Figura 1. Dinosaurio (Pacheco, 2013).

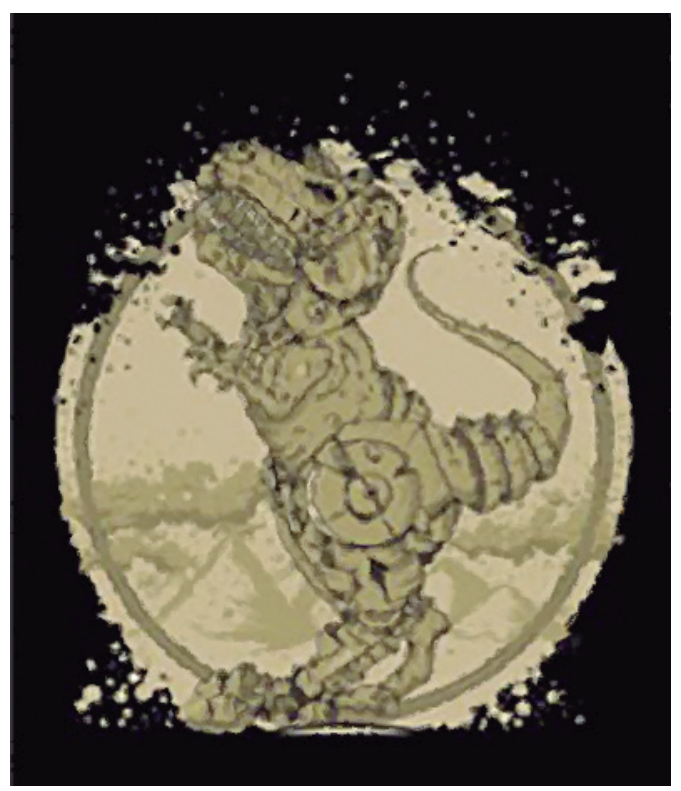




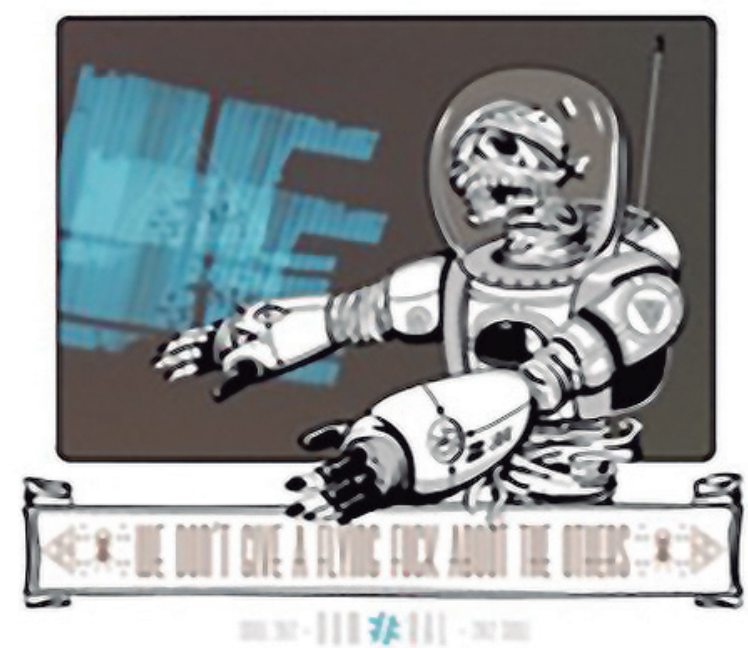

Figura 2. Astronomía (Dávila, 2013).

Estas opiniones son algunas de las miradas de cómo se está desarrollando la ilustración en el diseño gráfico en la ciudad de Cuenca. Si bien esta disciplina no ha tenido un crecimiento acelerado como se esperaba, ha demostrado el potencial que existe y queda por explotar en muchos diseñadores gráficos ilustradores. Este desarrollo se basa en la importancia que muestran las empresas que se desenvuelven en la industria gráfica al talento de ilustración proporcionado por muchos diseñadores gráficos de Cuenca siendo estos profesionales capaces para crear competencia.

Relación entre el diseño gráfico y la industria textil

En la industria gráfica, el diseño gráfico y sus varias aplicaciones es un colaborador indispensable dentro de la industria textil. La pregunta que tienen las personas es ¿Cómo el diseño gráfico se logra desarrollar y entretejer en la moda? La respuesta está en la calidad de las técnicas utilizadas por los diseñadores gráficos como es la ilustración, la tipografía, el diseño de logotipos, entre otros. Muchos diseñadores gráficos han generado marcas textiles así como también trabajan para éstas, aportando con sus creaciones gráficas. La necesidad de nuevos diseños en la moda textil contemporánea exige que se utilice y se explore más de las nuevas expresiones artísticas que llevan a las tendencias modernas, con lo cual los trabajos de ilustración de muchos diseñadores gráficos llegan a formar parte de esta industria.

Según Carlos Vidal (2010) el diseño gráfico aplicado en la industria de la moda es una actividad creciente en grandes ciudades donde se ha adaptado rápidamente. Los diseñadores gráficos que trabajan en ilustración pueden vincularse en la moda, ya que las artes gráficas han tenido una evolución en la industria, provocando que el sector busque nuevos servicios gráficos. Los diseñadores gráficos constantemente están 
trabajando para convertir sus creaciones en imágenes agradables para las personas, imágenes auténticas, novedosas e interesantes con las que las personas se pueden identificar y lucir.

De esta manera se puede decir que el diseño gráfico forma parte importante en el mundo de la moda, ya que es evidente identificar en la vestimenta de las personas, ilustraciones, logos, frases que llevan estampados y no necesariamente estas imágenes corresponden a una moda o un estilo en específico (Abaestudio, 2014). Existen prendas con todo tipo de diseño, que están al gusto y preferencia del consumidor cubriendo toda edad, género y cultura. De esta manera, el trabajo de diseñadores gráficos ha permitido encontrar una libre expresión por medio de la vestimenta con lo que trata de llenar esos espacios que tienen distintos matices en los gustos del consumidor ante la moda.

Para conocer la eficiente relación del diseño gráfico con la industria textil, y cómo se desenvuelve el trabajo de ilustración de los diseñadores gráficos en la moda y su marcada importancia hoy en día, se exponen a continuación algunos ejemplos de diseñadores gráficos que laboran en esta área, como son:

- Joan Tarragó, ilustrador español que tiene su estudio en Barcelona; sus trabajos incluyen personajes humanos, animales, paisajes líneas y texturas. Joan ha trabajado para importantes marcas como Converse, Quiksilver, Nike, Ambiguous y Rayban.

- Paul Boudens, diseñador gráfico e ilustrador proveniente de Bélgica. Boudens trabaja actualmente para el diseñador de modas Yohji Yamamoto (Delfino, 2007).

- Joshua M. Smith es un diseñador gráfico de 40 años, estadounidense, nacido en Indiana y radicado en Orlando; dedicado a la pintura, tipografía, diseño de logos e ilustración. Joshua en sus trabajos, que han formado parte de la industria textil ha colaborado con marcas reconocidas como son: Harley Davidson, Levi's, Adidas, Nike, Billabong, Quicksilver, Hurley (Área Visual, 2014).

- El equipo compuesto por los alemanes Attila Szamosi y Lars Wunderlich, dos diseñadores gráficos e ilustradores quienes empezaron a trabajar juntos desde el 2005 y se hacen llamar Peach Beach, quienes de a poco fueron alcanzando renombre en el medio, y logrando trabajar para marcas como Amazon, Nike, Google, Converse, Dell entre las más destacadas (Indio, 2014).

- Andrés Colmenares otro diseñador gráfico e ilustrador venezolano, fundador de la marca Wawawiwa, desde el 2005 dedicada a la venta de prendas de vestir en su mayoría por medio de la web, se ha caracterizado por crear ilustraciones cómicas para estampar en las prendas de vestir como camisetas, chompas, bolsos. Las ilustraciones que llevan las prendas son de edición limitada, por lo que siempre está creando nuevos diseños para remplazar cada colección (Wawa wiwa desing, 2014).

- Chow Hon Lam es un diseñador gráfico e ilustrador del país de Malasia, quien crea ilustraciones para camisetas. Chow ha ganado múltiples premios a lo largo de su carrera como diseñador gráfico e ilustrador (Flyingmouse 365, 2014); alrededor de 100.000 camisetas con los diseños de Chow han sido vendidas, logrando tener un re- 
conocimiento alto por su trabajo. Chow ha colaborado también con marcas como Nike, AirAsiaAirlines, Lotus, Klue, MARTELL VSOP (Behance, 2014).

Como se puede apreciar estos son diseñadores gráficos que han incluido la ilustración en la industria textil, por lo que la cantidad de profesionales y personas dedicadas al arte de la ilustración que han sido incluidos en la industria textil es cada vez más creciente, con lo que se muestran nuevas tendencias, se crean nuevas modas y se intenta satisfacer los gustos y preferencias de los consumidores cada vez más completos y exigentes.

\section{Estudio de mercado para la creación de una nueva marca}

Esta herramienta servirá para identificar las oportunidades que puedan materializar este proyecto, y tener una visión clara de cómo actúa el mercado antes del momento de tomar decisiones. Este proceso sistemático de investigación exige utilizar eficientemente los recursos que se disponen, buscar los métodos y técnicas necesarias que generen resultados confiables y acertados.

\section{Problema de la investigación}

La industria textil nacional basa su producción en diseños foráneos y repetitivos, descuidando la intervención del diseñador local. Esto deja un espacio libre para las propuestas de ilustración de diseñadores gráficos, ya que la industria textil no ha presentado nuevas propuestas de ilustración gráfica y diseños relacionadas con las nuevas expresiones de artistas.

El incremento de diseñadores gráficos en el medio, que equivale a decir el aumento de talento local, se ve frenado en su expresión por falta de espacios o medios para que su trabajo sea plasmado, y peor aún comercializado. La industria local en sus dependencias requiere de los servicios de diseñadores gráficos en un número reducido y para tareas específicas, donde el diseñador 0 artista llega a ser un empleado considerado como mano de obra calificada, con lo que se frustran las capacidades expresivas de las personas creativas.

Las nuevas expresiones en obras dentro del diseño gráfico y la ilustración, realizadas por los diferentes diseñadores gráficos no siempre tienen el medio para poder presentarse, por lo que esta propuesta trata de ocupar ese espacio con una nueva marca para que estas propuestas y expresiones sean impresas en los productos textiles. Como consecuencia existe la incertidumbre de la aceptación de la marca por el consu-

midor en la ciudad de Cuenca, como también de la probabilidad de colaboración de los diseñadores gráficos ilustradores para elaborar los productos con la marca.

\section{Preguntas de la investigación}

¿Cuál es la factibilidad comercial de establecer una nueva marca textil donde el diseñador gráfico cuencano pueda presentar sus ilustraciones y vender sus obras 
mediante estos productos textiles?

En consecuencia, esta pregunta se divide en dos más que serán el cuerpo del proceso de la investigación para cumplir con el objetivo planteado de conocer qué factibilidad tiene implantar una nueva marca textil. Estas son:

¿Qué aceptación tendría en el mercado una nueva marca textil local que incluyera el trabajo de lustración?

¿Cuánta colaboración se puede obtener de los diseñadores gráficos ilustradores cuencanos con sus trabajos para los productos de la marca?

\section{Objetivos de la investigación}

Objetivo general:

Analizar la factibilidad comercial para establecer una nueva marca en productos textiles como camisetas, casacas y chompas, que incluya la ilustración gráfica en el diseño.

Objetivos específicos:

Determinar la aceptación de la marca en el mercado.

Determinar la aceptación de colaboración de los diseñadores gráficos ilustradores cuencanos.

\section{Diseño de la investigación}

Para la investigación se trabajó con fuentes primarias y secundarias; las fuentes primarias cualitativas realizadas con el fin de conocer datos que sean necesarios para el estudio, como las decisiones y motivaciones más profundas en el momento de compra para las personas y sus comportamientos. Esto se realizó mediante la técnica de las entrevistas a expertos para obtener esta información, seleccionando a personas que puedan dar información útil, como diseñadores gráficos, diseñadores gráficos ilustradores, diseñadores textiles, comerciantes y fabricantes textiles que son los que se desenvuelven dentro de este mercado.

Entre las fuentes primarias cuantitativas están los datos recogidos por las encuestas a los dos grupos, diseñadores gráficos y a los consumidores, encuestas basadas en la muestra de la población de Cuenca, segmentada con variables de edad, nivel socioeconómico, y ubicación demográfica. Con las encuestas se recolectó toda la información relacionada como comportamientos, gustos, preferencias, motivaciones, y capacidad de pago del consumidor.

Entre las fuentes de información secundarias externas se cuentan con datos estadísticos que se pueden encontrar en el Instituto Nacional de Estadísticas y Censos INEC, ECV (Encuestas de condiciones de vida), Universidad del Azuay, Universidad de 
Cuenca, como también información de diferentes organismos textiles del país.

\section{Investigación cualitativa}

La investigación cualitativa se realizó mediante entrevistas a expertos con diferentes diseñadores gráficos, diseñadores gráficos ilustradores, diseñadores textiles, y productores o comerciantes textiles, con la idea de que todos estos puedan aportar con información de las oportunidades 0 amenazas que puede tener una marca textil en el mercado. Algunas de las preguntas son: ¿Qué relaciones se pueden obtener de la ilustración en la moda? ¿Qué tendencias utilizan los diseños en la industria textil local? ¿Cómo se desarrolla la industria textil en el medio local?, entre otras.

\section{Las personas entrevistadas fueron las siguientes:}

- Diseñadores gráficos: Roberto Ortiz, Daniel Vicuña y Paola Rodríguez.

- Diseñadores gráficos ilustradores: Johnny Gavilanes e Isaac Flores.

- Diseñadores textiles: Cristina López, Ihua Lee y Rosana Corral.

- Productores y comerciantes textiles: María José Machado (creadora de la marca Cu. Gallery) y Efraín Pacheco (creador de la marca Jean Le Roux).

Investigación cuantitativa en diseñadores gráficos y consumidores

Las encuestas se realizarán a los habitantes de la ciudad de Cuenca, como también a los diseñadores gráficos de la misma ciudad.

\section{Encuestas a diseñadores gráficos}

Para realizar la investigación cuantitativa a los diseñadores gráficos de la ciudad de Cuenca se procedió a investigar el dato exacto de graduados con el título de diseñadores gráficos, en la Universidad de Cuenca como la Universidad del Azuay, ya que son las dos únicas universidades que ofrecen dicha carrera.

La Universidad de Cuenca tiene 97 graduados en la carrera de diseño gráfico desde el año 2008 (Universidad Estatal de Cuenca, 2015).

La Universidad del Azuay ha profesionalizado a 180 personas en la carrera de diseño gráfico desde el año 2006. (Universidad del Azuay, 2015).

Este dato suma la cantidad de 277 diseñadores gráficos en la ciudad de Cuenca, información que será utilizada para conseguir la muestra poblacional para la realización de encuestas a los mismos. La investigación cuantitativa a diseñadores gráficos 
permite conocer el interés, motivación, actividades, y probabilidades que tienen los diseñadores en trabajar o colaborar con una marca textil local.

Para encontrar el tamaño de la muestra se utilizó el método no probabilístico donde se aplicó la muestra por conveniencia. La justificación del uso de este método es que se cuenta con un universo pequeño que es de 277 diseñadores gráficos de la ciudad de Cuenca, de este dato se posee la mitad de contactos válidos para poder solicitar la ayuda del entrevistado; 59 personas estuvieron de acuerdo con contestar los cuestionarios, al final se contó con una muestra de 60 personas que optimistamente puede satisfacer la meta buscada en la investigación (Kinnear, 1998).

\section{Encuestas a los consumidores}

La investigación cuantitativa se realizará mediante encuestas que serán realizadas en la ciudad de Cuenca utilizando el método probabilístico simple, cuya muestra será filtrada mediante las siguientes variables:

En el cantón Cuenca se filtra a la zona urbana, con edades comprendidas entre los 17 y 28 años con un nivel socioeconómico medio, medio alto, alto. Las variables utilizadas para hallar la muestra y realizar la investigación son producto de la ejecución de un grupo focal en el que se trataron temas sobre los gustos y preferencias de los consumidores ante los productos textiles, posibilidades de compra, accesibilidad al producto, entre otras.

El dato utilizado para esta etapa es producto de la base de datos del censo 2010. El proceso de muestreo de la población se da de la siguiente manera: la población del cantón Cuenca es de 505.585 habitantes, la población de la zona urbana del cantón Cuenca es de 331.888 habitantes, filtrando en este dato los habitantes de edades entre 17 y 28 años el resultado es de 80.445 habitantes (INEC, 2010). La tasa de pobreza del cantón Cuenca en el área urbana es de 21,92\%, en consecuencia el $78,08 \%$ pertenece a la población de nivel socioeconómico medio en adelante (Sistema Nacional de Información, 2010). El resultado final es 62.811 habitantes.

Esta fórmula se aplica para poblaciones finitas, sabiendo que la población a investigar ha sido filtrada, se obtuvo un número menor a los 100.000 habitantes (Benassini, 2009).

La aplicación de la fórmula es la siguiente:

Por lo tanto, el resultado muestra que se deben realizar 398 encuestas en la población de Cuenca, a personas entre 17 y 28 años que se dividen en 3 grupos por edades que son: entre 17 y 20 años, entre 21 a 24 años, y de 25 a 28 años de edad. Estos grupos se dividirán en un número igual de encuestas. Otro dato como el nivel socioeconómico de medio en adelante, se puede definir por los lugares donde se van a 
desarrollar las encuestas, como por observación y diferentes métodos del encuestador para definir a las personas requeridas para este proceso.

Por otra parte también se espera encuestar a un $50 \%$ de hombres y el otro $50 \%$ mujeres, ya que como resultado del grupo focal se definió que el producto a investigar es consumido por ambos géneros casi de manera igual.

\section{Análisis de la factibilidad de la creación de la marca}

Los resultados se podrían separar entre los hallazgos positivos, negativos y neutrales; estos serían los hallazgos cuyo análisis más profundo dependerá de la siguiente etapa de desarrollo del proyecto. Estos se explicarán en cada uno de ellos.

\section{Hallazgos en la investigación cualitativa}

En este punto se analizan los hallazgos encontrados en las entrevistas a expertos, donde se toma en cuenta la información más importante que puede ser utilizada para conocer la factibilidad del proyecto. Esto según el criterio del investigador.

\section{Entrevistas a diseñadores gráficos}

Hallazgos positivos:

- El diseño gráfico puede vincularse exitosamente con la industria textil, se pueden lograr grandes resultados con la experimentación en la parte creativa.

- La ilustración en la industria textil es algo que se utiliza comúnmente, las ilustraciones pueden agregar valor a las prendas según lo que el artista pueda plasmar.

- Los diseños de las prendas textiles de marcas locales están en un proceso de desarrollo. Esto puede presentar nuevas oportunidades para los productores textiles, para innovar el diseño y crear nuevas propuestas.

Hallazgos negativos:

- Las nuevas expresiones de diseño gráfico pueden ser difíciles de introducir en la sociedad, las tendencias van por el lado más publicitario comercial.

Entrevistas a diseñadores gráficos ilustradores

Hallazgos positivos:

- La ilustración gráfica se puede fusionar exitosamente con la industria textil

- La experimentación y el constante cambio en la moda permite utilizar las nuevas expresiones artísticas de la ilustración grafica en la industria textil. 
- La aceptación de la sociedad ante las nuevas expresiones artísticas ha sido bien recibida motivando a los artistas a explorar más este arte.

- La utilización de ilustraciones en una marca textil puede ser favorable para la marca como también promueve el trabajo artístico de sus autores.

- El diseño en las marcas textiles locales se desarrolla rápidamente mostrando exclusividad y calidad en sus productos.

\section{Entrevistas a diseñadores textiles}

Hallazgos positivos:

- La ilustración es fundamental en la industria textil para desarrollar un buen producto.

- Utilizar los trabajos de ilustración de diferentes diseñadores gráficos en productos textiles es algo provechoso que complementa la producción textil.

- Las nuevas expresiones artísticas siempre están vinculadas con la industria textil ya que la moda y el arte siempre avanzan con la contemporaneidad.

Hallazgos negativos:

- Las marcas textiles locales todavía están en desarrollo y proceso de mejora.

\section{Entrevistas a productores y comerciantes textiles}

Hallazgos positivos:

- El aporte de trabajos de ilustración de diferentes diseñadores gráficos es una propuesta viable y de éxito por la variedad de buenos artistas locales.

- Las prendas más vendidas en el mercado textil son camisetas.

Hallazgos negativos

- La industria textil local es compleja y no siempre rentable.

- Las debilidades que tienen las marcas textiles locales son la calidad, diseños y acabados.

- El consumidor cuencano, por lo general, se sujeta a las tendencias contemporáneas de la moda textil.

Hallazgos en la investigación cuantitativa a diseñadores gráficos

El resumen de los resultados más relevantes es: 


\begin{tabular}{|c|l|c|}
\hline CÓDIGO & \multicolumn{1}{|c|}{ VARIABLE } & RESULTADOS \\
\hline $\mathbf{a}$ & Diseñadores gráficos que desempeñan su profesión actualmente & $93 \%$ \\
\hline $\mathbf{b}$ & La mayoría de diseñadores gráficos actualmente trabajan como: & Empleados (39\%) \\
\hline $\mathbf{c}$ & $\begin{array}{l}\text { Aplicación en la que los diseñadores gráficos tienen más } \\
\text { conocimiento y experiencia }\end{array}$ & $\begin{array}{c}\text { Diseño corporativo } \\
(13 \%)\end{array}$ \\
\hline $\mathbf{d}$ & Diseñadores gráficos ilustradores & $8 \%$ \\
\hline $\mathbf{e}$ & $\begin{array}{l}\text { Personas que han aplicado la ilustración gráfica en trabajos } \\
\text { de diseño gráfico }\end{array}$ & $83 \%$ \\
\hline $\mathbf{f}$ & Diseñadores gráficos que han trabajado en proyectos textiles & $52 \%$ \\
\hline $\mathbf{g}$ & $\begin{array}{l}\text { Opiniones positivas sobre la vinculación de diseñadores gráficos } \\
\text { en la industria textil (proceso creativo) }\end{array}$ & $100 \%$ \\
\hline $\mathbf{h}$ & $\begin{array}{l}\text { Aceptación de diseñadores gráficos para colaborar con sus trabajos } \\
\text { de ilustración para plasmarlos en prendas textiles a cambio de } \\
\text { un beneficio económico }\end{array}$ & $97 \%$ \\
\hline $\mathbf{i}$ & Aceptación de diseñadores gráficos ilustradores a la propuesta & $100 \%$ \\
\hline
\end{tabular}

Tabla1: Resultados más relevantes de diseñadores gráficos. Encuestas a diseñadores gráficos (Pacheco, 2015).

Hallazgos positivos:

- La mayoría de diseñadores gráficos, incluyendo a los diseñadores gráficos ilustradores, desempeña actualmente su profesión.

- Una cantidad considerable de diseñadores gráficos ha trabajado en proyectos con productos textiles.

- Todos los diseñadores gráficos aseguran poder vincular su trabajo de diseño con la parte creativa de elaboración de productos textiles.

- Casi todos los diseñadores gráficos encuestados aceptaron la propuesta de vincular sus trabajos de ilustración con una marca textil, para plasmarlos en productos textiles con su firma, a cambio de un beneficio económico.

Hallazgos neutrales:

- Los diseñadores gráficos ilustradores trabajan casi equitativamente como diseñadores freelance ${ }^{1}$, empleados y en negocios propios. En este caso se encontró solo un hallazgo que podría ser analizado posteriormente, ya que en caso de materializarse el proyecto es necesario conocer cuántos de los diseñadores gráficos ilustradores tienen la disponibilidad, como el compromiso de ser parte del proyecto. 
Hallazgos en la investigación cuantitativa a consumidores

El resumen de los resultados más relevantes es:

\begin{tabular}{|c|c|c|c|}
\hline CÓDIGO & VARIABLE & \multicolumn{2}{|c|}{ RESULTADOS } \\
\hline a & Personas que adquieren estos productos textiles: camisetas, casacas, chompas & \multicolumn{2}{|c|}{$100 \%$} \\
\hline b & Frecuencia de la adquisición de prendas de vestir (camisetas, casacas, chompas) & \multicolumn{2}{|c|}{ Trimestral (40\%) } \\
\hline c & $\begin{array}{l}\text { Característica más tomada en cuenta al momento de la compra (camisetas, } \\
\text { casacas, chompas) }\end{array}$ & \multicolumn{2}{|c|}{ Diseño (35\%) } \\
\hline d & Prenda de mayor frecuencia de compra (camisetas, casacas, chompas) & \multicolumn{2}{|c|}{ Camisetas (54\%) } \\
\hline e & Medio de comunicación más usado para conocer nuevas marcas textiles & \multicolumn{2}{|c|}{ Internet (60\%) } \\
\hline f & Personas que han comprado prendas por internet & \multicolumn{2}{|c|}{$51 \%$} \\
\hline \multirow{6}{*}{ g } & \multirow{6}{*}{ Calificaciones de características de marcas textiles nacionales. } & Calidad & $3(42 \%)$ \\
\hline & & Moda & $3(43 \%)$ \\
\hline & & Precio & $3(43 \%)$ \\
\hline & & Adquisición & $3(34 \%)$ \\
\hline & & $\begin{array}{l}\text { Variedad de } \\
\text { diseños }\end{array}$ & $\begin{array}{l}3(31 \%) \\
2(30 \%)\end{array}$ \\
\hline & & Publicidad & $2(36 \%)$ \\
\hline h & Personas que han comprado ropa de marca nacional & \multicolumn{2}{|c|}{$79 \%$} \\
\hline $\mathbf{i}$ & Personas que conocen marcas textiles locales (Cuenca) & \multicolumn{2}{|c|}{$72 \%$} \\
\hline j & Aspecto más considerado al momento de elegir una marca textil & \multicolumn{2}{|c|}{ Diseño (33\%) } \\
\hline \multirow{3}{*}{ k } & \multirow{3}{*}{ Precio dispuesto a pagar por las prendas actualmente usadas por las personas } & Camisetas & $\begin{array}{c}\$ 11 \text { a } \$ 20 \\
(45 \%)\end{array}$ \\
\hline & & Casacas & $\begin{array}{c}\$ 41 \text { a } 50 \$ \\
(36 \%)\end{array}$ \\
\hline & & Chompas & $\begin{array}{c}\$ 21 \text { a } 35 \$ \\
(41 \%)\end{array}$ \\
\hline $\mathrm{I}$ & Lugar más concurridido de la ciudad para comprar prendas de vestir & \multicolumn{2}{|c|}{ Centro de la ciudad (39\%) } \\
\hline m & $\begin{array}{l}\text { Personas que estarían dispuestas a probar una nueva marca textil (camisetas, } \\
\text { casacas, chompas) en la que se plasmen diseños e ilustraciones de diseñadores } \\
\text { gráficos locales }\end{array}$ & \multicolumn{2}{|c|}{$93 \%$} \\
\hline \multirow{3}{*}{ n } & \multirow{3}{*}{$\begin{array}{l}\text { Disposición de pago de las personas por prendas (camisetas, casacas, chompas) } \\
\text { con las características mencionadas. }\end{array}$} & Camisetas & $\begin{array}{l}\$ 11 \text { a } \$ 20 \\
(53 \%)\end{array}$ \\
\hline & & Casacas & $\begin{array}{c}\$ 26 \text { a } 40 \$ \\
(45 \%)\end{array}$ \\
\hline & & Chompas & $\begin{array}{l}\$ 21 \text { a } 35 \$ \\
(50 \%)\end{array}$ \\
\hline
\end{tabular}

Tabla2: Resultados más relevantes de consumidores. Encuestas a consumidores (Pacheco, 2015). 
Hallazgos positivos:

- Todos los encuestados adquieren prendas como camisetas, casacas o chompas.

- La frecuencia de compra de prendas como camisetas, casacas y chompas es en su mayoría, en períodos trimestrales y mensuales.

- La característica más tomada en cuenta al comprar una camiseta casaca o chompa es el diseño que tenga la prenda.

- Las camisetas, casacas y chompas son las prendas más compradas por los encuestados.

- Las calificaciones positivas a distintas características que pueden poseer las prendas de marcas nacionales son para la calidad, los precios y la fácil adquisición.

- La mayoría de encuestados ha comprado o compra ropa de marcas nacionales.

- El aspecto más importarte al momento de seleccionar una marca textil son los diseños.

- La mayoría de encuestados aceptó la propuesta de una marca en la que se incluyen diseños e ilustraciones de diseñadores gráficos cuencanos en productos como camisetas, casacas y chompas.

- El estimado de pago por una camiseta con las características mencionadas de una nueva marca está en un rango medio y medio alto.

- El estimado de pago por una casaca con las características mencionadas de una nueva marca está en un rango medio y medio alto.

- El estimado de pago por una chompa con las características mencionadas de una nueva marca está en un rango medio y medio alto.

Hallazgos neutrales:

Estos hallazgos del análisis de investigación se los llamaría neutrales, ya que esta información no presenta un aspecto negativo para la factibilidad. Se puede demostrar como información positiva analizándola en las etapas posteriores de ejecución del proyecto, por ejemplo: en las proyecciones de ventas, proyecciones de costos y gastos, punto de equilibrio, plan de negocio, plan de mercadotecnia, etc.

- El internet es el medio más utilizado por los encuestados para conocer nuevas marcas textiles.

- La mayoría de encuestados ha realizado compras de ropa por internet.

- El estimado de pago por una camiseta que actualmente usarían los encuestados está en un rango medio, medio alto.

- El estimado de pago por una casaca que actualmente usarían los encuestados está en un rango medio, medio alto.

- El estimado de pago por una chompa que actualmente usarían los encuestados está en un rango medio, medio alto.

- El lugar más concurrido por los encuestados en la ciudad de Cuenca para realizar sus 
compras de prendas de vestir son las boutiques del centro de la ciudad.

Hallazgos negativos

- Los encuestados dieron calificaciones bajas a ciertas características de prendas de marcas nacionales, ya que pueden estar insatisfechos 0 inconformes con aspectos como son la moda (prendas de vestir con modas desactualizadas), los diseños (los diseños de las prendas pueden ser escasos, poco trabajados, o desactualizados con las tendencias actuales) y la publicidad (no existe campañas publicitarias por parte de las marcas textiles nacionales para dar a conocer sus productos a los consumidores).

- La mayoría de los encuestados no tiene conocimiento de marcas textiles locales (ciudad de Cuenca). Muchos de los consumidores cuencanos no tiene conocimiento de la existencia de marcas textiles locales ni de su participación en el mercado.

\section{Resultado final del análisis de factibilidad}

El análisis de los resultados obtenidos por la investigación del proyecto ha dado oportunidades a la ejecución del mismo. Existe una gran cantidad de información positiva que suma las posibilidades de materialización del proyecto.

Según el análisis de los resultados se asegura la factibilidad de la propuesta de establecer una nueva marca textil donde se incluyan trabajos de ilustración de diferentes diseñadores gráficos cuencanos. Los resultados de la investigación cuantitativa a diseñadores gráficos no presentan ningún hallazgo negativo que pueda impedir 0 dificultar la colaboración de los diseñadores gráficos con la marca. Los resultados de la investigación cuantitativa a consumidores presentan dos hallazgos negativos que muestran el desconocimiento y poca aceptación en ciertos aspectos de las marcas textiles locales. Estos resultados muestran debilidades que presenta la industria textil local en el mercado, información que servirá para desarrollar las estrategias necesarias para solucionar y mejorar estas falencias encontradas, procesos que serán solucionados en las siguientes etapas del proyecto.

En la investigación cualitativa con el método de entrevista a expertos, se obtuvieron 5 hallazgos negativos que informan inconvenientes acerca de la experimentación, innovación y producción de calidad en la industria textil local, también a veces se pueden presentar dificultades en implantar diferentes tendencias y modas en la sociedad.

A pesar de estos puntos negativos se cuenta con una gran cantidad de hallazgos positivos que hacen posible y factible la propuesta de implementar una marca textil con las características que se proponen en esta investigación conociendo el potencial artístico que existe en la ciudad dentro de la disciplina de la ilustración gráfica, la misma que se puede llegar a expandir si se dispone de los recursos necesarios. Asimismo siguen existiendo oportunidades en la industria textil siempre que exista 
innovación en los productos para brindar al consumidor opciones nuevas, llamativas y actuales con las tendencias globales. La fusión propuesta puede llegar a generar varias oportunidades para todos los que se involucran en este proyecto como son diseñadores gráficos, ilustradores, comerciantes y productores textiles, para satisfacer las necesidades y deseos de los consumidores, quienes se complacerán de llevar arte en una prenda de vestir. 
Notas

1. Freelance: trabajo realizado por una persona de manera autónoma. De esta manera el trabajador desempeña su profesión por propia cuenta, brindando sus servicios a sus clientes.

\section{Referencias bibliográficas}

Abaestudio. (2014). El diseño gráfico aplicado al mundo de la moda. Recuperado de http://www.abaestudio.com/el-diseno-grafico-aplicado-al-mundo-de-la-moda

Almela, R. (2006). Ilustración. Recuperado de Fernando Muñoz: http://www.fernandomunoz.com/el_ baul/rafaeldepenagos_09.html

Almela, R. (2008). ¿Arte o diseño? Recuperado de Homines: http://www.homines.com/arte_xx/ilustracion_arte_diseno/index.htm

Área Visual. (2014). Los diseños e ilustraciones de Hydro 74. Recuperado de http://www.area-visual. com/2014/06/los-disenos-e-ilustraciones-de-hydro74.html

Asociación de industriales textiles del Ecuador. AlTE. (2014). Asociación de industriales textiles del Ecuador. Recuperado de http://www.aite.com.ec/index.php?option=com_phocadownload\&view $=$ section\&id=2:estadisticas-de-comercio-exterior-textil\&ltemid=19

Behance. (2014). Behance. Recuperado de https://www.behance.net/flyingmouse

Benassini, M. (2009). (2da ed.). Introducción a la investigación de mercados: Un enfoque para América Latina. México: Pearson Educación.

Dávila, J. (2014). Entrevista personal. (M. Pacheco, Entrevistador)

Delfino, M. (2007). Diseño gráfico y moda. Recuperado de http://www.pagina12.com.ar/diario/suplementos/m2/10-1174-2007-04-09.html

Flyingmouse 365. (2014). About flying mouse 365. Recuperado de http://flyingmouse365.com/stores/ about-flying-mouse.html

Fuentes, M. (2013). Oportunidades comerciales en el Ecuador para la industria textil. Recuperado de http://sbnetwork.net/oportunidades-comerciales-en-ecuador-para-la-industria-textil/

Indio. (2014). ¿Conocen a Peach Beach? Recuperado de http://www.indio.com.mx/node/6310

Kinnear, T., \& Taylor, J. (1998). Investigación de mercados: Un enfoque aplicado. Santa fé de Bogotá: McGraw-Hill.

Ochoa, D. (2013). Bitácora. Un libro de ilustración cuencana. Recuperado de http://issuu.com/diegoochoa9/docs/bitacora_final_imprimir

Pacheco, S. (2014). Entrevista personal. (M. Pacheco, Entrevistador).

Sistema Nacional de Información. (2010). Indicadores de pobreza. Recuperado de

http://indestadistica.sni.gob.ec/QvAJAXZfc/opendoc.htm?document=SNI.qvw\&host=0vS@kukuri\&anonymous=truehttp://indestadistica.sni.gob.ec/QvAJAXZfc/opendoc.htm?document=SNI. qvw\&host=QVS@kukuri\&anonymous=true\&bookmark=Document/BM27http://indestadistica. sni.gob.ec/QvAJAXZfc/opendoc.htm?document=SNI.qvw\&host=0VS@kukuri\&anonymous=truehttp://indestadistica.sni.gob.ec/QvAJAXZfc/opendoc.htm?document=SNI.qvw\&host=QvS@ kukuri\&anonymous $=$ true\&bookmark=Document/BM27 
Universidad Estatal de Cuenca. (2015). Graduados de la carrera de Diseño Gráfico.

Universidad del Azuay. (2015). Graduados de la carrera de Diseño Gráfico.

Vidal, C. (2010). 10 carreras de la industria de la moda. Recuperado de http://www.carrerasconfuturo. com/2010/06/23/10-carreras-de-la-industria-de-la-modal

Wawa wiwa desing. (2014). Andrés Colmenares. Recuperado de http://wawawiwadesign.com/catalogo. php

Figuras

Figura 1. Dávila, J. (2013). Astronomía.

Figura 2. Pacheco, S. (2013). Dinosaurio.

Tablas

Tabla 1. Pacheco, M. (2015). Resultados más relevantes de Diseñadores Gráficos.

Tabla 2. Pacheco, M. (2015). Resultados más relevantes de Consumidores. 